\title{
Analysis of high school students' mastery in light wave theory using structured inquiry learning assisted by a virtual laboratory
}

\author{
E. Puspitaningtyas, E. Fandira Nasera Putri, Umrotul and Sutopo \\ Universitas Negeri Malang (State University of Malang, Indonesia). \\ e-mail: puspitaellen@gmail.com; emiliafandira@gmail.com; \\ umrotul.1903218@students.um.ac.id; sutopo.fisika@um.ac.id
}

Received 8 June 2020; accepted 10 July 2020

\begin{abstract}
Structured inquiry-based learning assisted by a virtual laboratory is necessary for senior high students to help their conceptual mastery of wave optics. Evaluation of the effectiveness of the method was performed through the analysis of quantitative and qualitative data. Quantitative data of student understanding of light wave theory was obtained from the implementation of a pre- and a post-test to students from a high school physics group. Meanwhile, qualitative data was collected from observation, student reasoning, and interviews before and after the structured inquiry-based learning lesson was given. The results of inquiry-based learning assisted by a virtual laboratory were found to improve the students' conceptual mastery of wave optics. Furthermore, it also has been found that students still have some difficulties with interference and diffraction after learning.
\end{abstract}

Keywords: Structured inquiry; virtual laboratory; conceptual mastery; light wave; physics education.

PACS: 01.40.Fk; 01.40.gb; 01.50.Lc.

DOI: https://doi.org/10.31349/RevMexFisE.18.10

\section{Introduction}

The important objective of learning physics is to master the basic concepts of physics to solve problems in everyday life $[1,2]$. Students tend to be able to solve mathematical equation problems relatively quickly, but the difficulty arises in solving problems applying concepts [3]. The struggling is because students only use mathematical equations when attempting to solve problems without understanding the concepts that underlie these mathematical equations [4]. Therefore, students are expected to gain a deep mastery of concepts in physics learning.

The overall undertanding of key concepts of light wave theory by high school students is relatively low. Based on research [5], as much as $16.67 \%$ of 100 high school students had difficulty learning about sound and light waves. The most common difficulty is that students tend to only use the geometric optics approach in analyzing the phenomenon of light waves, as found in the following studies. Students usually think that if the left gap in the double slit interference experiment is closed, then the left pattern formed on the screen will disappear because each gap responsible for half of the interference pattern [6,7]. Students also tend to think that when the width of a single gap is decreased then the bright central pattern formed on the screen will become narrower as well. This is because students' concepts about diffraction and image formation are still mixed [8].

According to Ref. [9], one of the sources for the difficulties that students face when understanding light wave material is the high degree of abstractness of the topic. The selection of inappropriate learning models become a factor in the lack of mastery of concepts $[5,10]$. For example, the conventional learning process -with its lack of activities- tends to make students adopt a passive role where they only listen to the explanations from their teachers.
Therefore, learning media that include visualization are needed to reduce the abstractness of the concept of light waves, one of which is the virtual laboratory. The virtual platform PhET [11] is a virtual laboratory that has main features, including visualization, effective calculation processes, and interactivity, where those features are very effective in helping students understand abstract concepts [12].

$\mathrm{PhET}$ provides a visualization of the topic of light waves, especially for interference and diffraction phenomena. By using wave interference simulations in PhET, interference can be shown through observing patterns on the screen when only use a single source also when use two coherent source. Wave interference simulations in PhET helps visualize the phenomenon of constructive interference and destructive light waves. Wave interference simulations in PhET displays wavefronts in the form of circular lines in each gap where overlapping lines will form bright patterns on the screen; otherwise, when the lines do not overlap, then dark screens will form. Besides, for the subtopics of double-slit interference and single slit diffraction, students can conduct experimental simulations by changing the quantities such as wavelength, screen distance to a gap, gap space, and gap width quickly. Then, students can directly observe changes that occur at a pattern formed on the screen.

Wave interference simulations in PhET as a learning medium must be used within the appropriate context and in the right way so that the benefits are optimal. One of them is by framing it in a conceptual change learning approach that allows students to develop new concepts and show the relationships between these concepts [12]. The inquiry is a science learning model that involves students to play an active role in finding the knowledge by asking and responding to questions, designing investigations, evaluating, and communicating their learning [13,14]. 


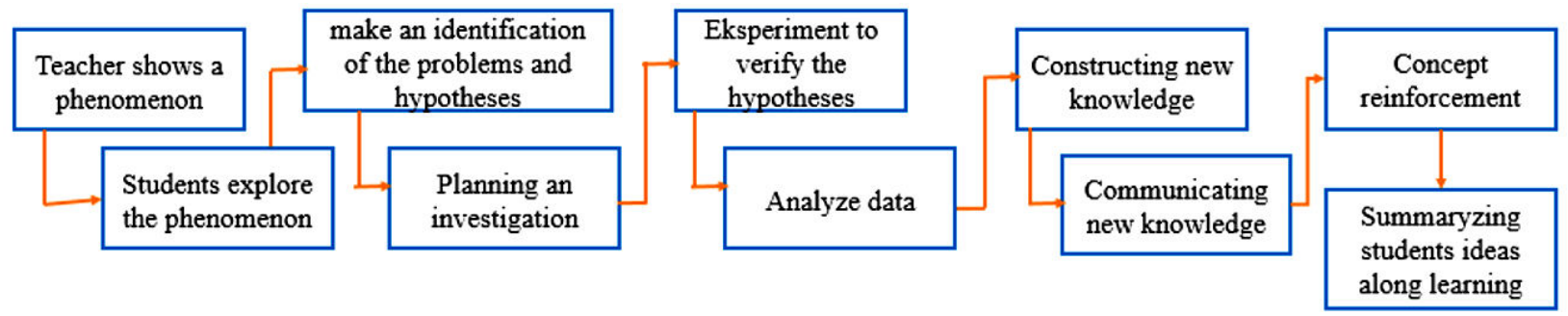

FIGURE 1. General sequence of learning by structured inquiry strategy.

TABLE I. Stage of structured inquiry learning.

\begin{tabular}{|c|c|c|}
\hline No & Stage & Activity \\
\hline 1 & $\begin{array}{l}\text { Exploration of } \\
\text { phenomena }\end{array}$ & $\begin{array}{l}\text { Students observe and try } \\
\text { to understand the problem } \\
\text { through the phenomena } \\
\text { presented by the teacher. }\end{array}$ \\
\hline 2 & $\begin{array}{c}\text { Formulate } \\
\text { statements } \\
\text { and hypotheses }\end{array}$ & $\begin{array}{l}\text { Students identify problems and } \\
\text { formulate hypotheses based } \\
\text { on the formulation of the } \\
\text { problem that has been made. }\end{array}$ \\
\hline 3 & $\begin{array}{c}\text { Plan } \\
\text { investigations }\end{array}$ & $\begin{array}{l}\text { Students gather with } \\
\text { their groups to study } \\
\text { trial procedure }\end{array}$ \\
\hline 4 & $\begin{array}{c}\text { Carry out } \\
\text { investigations }\end{array}$ & $\begin{array}{l}\text { Students conduct } \\
\text { experiments in groups then } \\
\text { write the data obtained into } \\
\text { the experiment table. }\end{array}$ \\
\hline 5 & $\begin{array}{c}\text { Analyze } \\
\text { data }\end{array}$ & $\begin{array}{l}\text { Students analyze the } \\
\text { results of the } \\
\text { experiment data. }\end{array}$ \\
\hline 6 & $\begin{array}{c}\text { Constructing } \\
\text { new knowledge }\end{array}$ & $\begin{array}{l}\text { Student formulating } \\
\text { conclusions then linking the } \\
\text { results experiment with } \\
\text { hypotheses that have } \\
\text { been previously formulated. }\end{array}$ \\
\hline 7 & $\begin{array}{l}\text { Communicating } \\
\text { new knowledge }\end{array}$ & $\begin{array}{l}\text { Each group presents their } \\
\text { work in class and group } \\
\text { discussions others may } \\
\text { ask questions or respond } \\
\text { to the presenter group }\end{array}$ \\
\hline
\end{tabular}

Source: Llewellyn (2013).

Structured inquiry learning is appropriate for high school students because they still need guidance in each inquiry until later they can do self-inquiry from beginning to end $[16,17]$. In structured inquiry learning, although students dominate learning actively, the teacher also plays an important role in giving direct problems to students to be investigated and providing step-by-step experimental procedures. Then students must find their own relationships between variables and draw conclusions $[18,19]$. Reference [20] argue that by structured inquiry learning, students are encouraged to work in small groups to solve problems, they are involved in the process of learning and it helps them undestand the topic and remember the information in the future.

In this study, we have applied a structured inquiry learning strategy to aid students in light wave theory. In particular, an example using this type of learning sequence was applied to the understanding of the interference concept in the context of the double slit experiment; the steps are described as follows. The teacher started the lesson by displaying an apperception picturing wave interference PhET simulations as shown in Fig. 2. The teacher proceeded to pose the following question to students: "Why are there differences in patterns that form on the screen when one source and two sources are used?"

Most of the students answered that in the second simulation there was interference, but they could not yet explain how dark and light patterns could form on the screen.

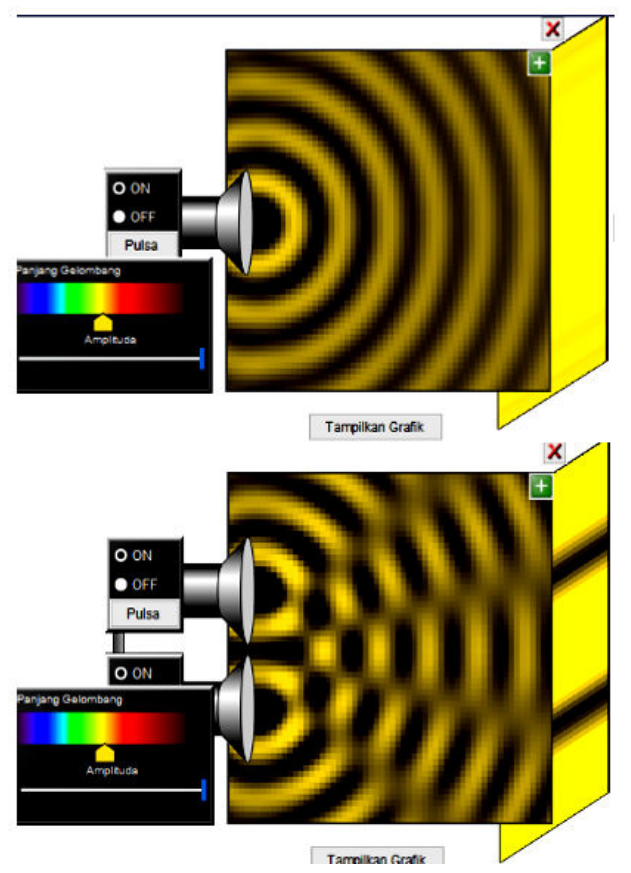

Figure 2. Apperception. 


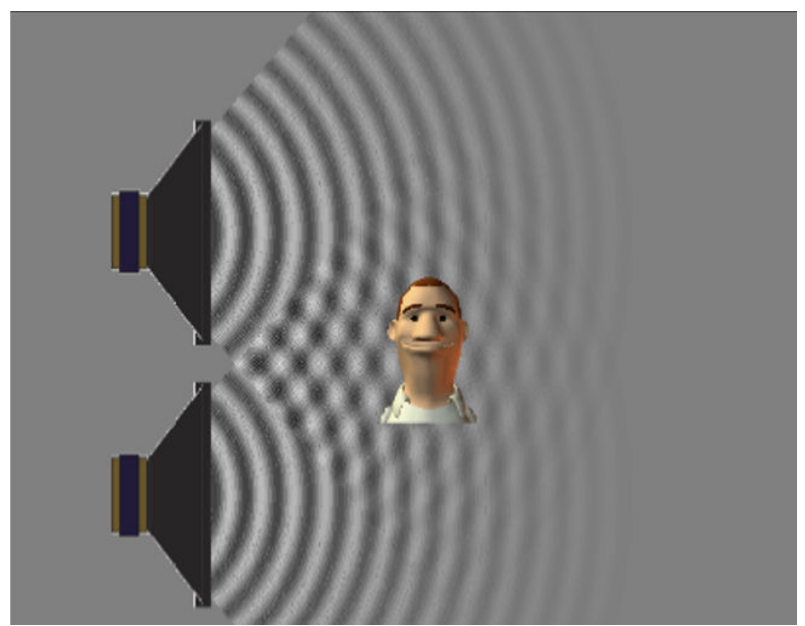

FIGURE 3. Review of sound wave interference.

Then, the teacher presented a PhET simulation demonstrating sound wave interference (see Fig. 3). The teacher associates loud and weak sounds of the resulting wave pattern to the constructive and destructive interference associated with bright and dark patterns on the light waves.

After that, the teacher asked one of the students to go to the front and demonstrate the fact that the light originating from two flashlights does not generate bright and light patterns on the screen, seemingly coming in conflict with the interference simulations. From these simulations and demonstrations, students are introduced to the concepts of light wave interference, constructive and destructive interference on light waves, and coherent and monochromatic waves.

The next step is exploration of the phenomenon. The teacher displays a wave interference in a PhET simulation related to double slit interference as shown in Fig. 4, and gives students some questions. "This simulation and the one on the apperception both use one source, but why are the dark and light patterns formed on the screen different?" The students

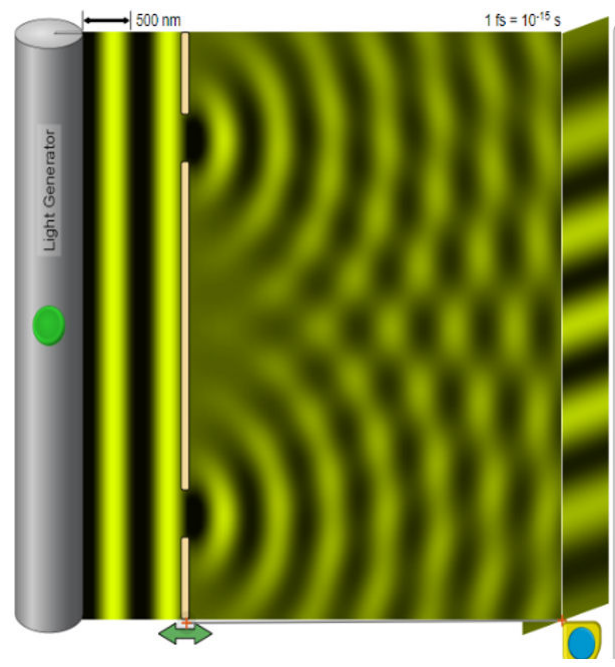

FIGURE 4. Double slit interference. answer that this is because in this simulation the source is passed through the slit.

The teacher proceeds to ask one more question: "To reach the same point on the screen, does the light from the top slit travel the same distance as the light from the bottom slit? Then, when I change the color of the light source, the distance of the screen to the slit, and the separation of the slite (done alternately), will the patter on the screen also change?". The students are then asked to reflect on the problem and come up with hypotheses based on the phenomenon just discussed.

After that, the teacher divides students into 8 groups and distributes worksheets to each group. The teacher guides students in conducting a double slit interference simulation experiment using wave interference simulations in PhET to test the hypotheses they have made before. The experiment was focused on finding the difference between the constructive and destructive interference paths in double slits and the relationship between wavelength, the distance from screen to the gap, and distance between slits and the distance between patterns formed on the screen.

After obtaining the data, students conduct group discussions to analyze the experimental data. In the process of deriving constructive and destructive interference equations in a double slit, students have difficulty in modeling the double slit experiment using geometric constructions so that the teacher always guides students in deriving these equations. After analyzing the data, students gain new knowledge and then compare it with hypotheses that have been previously made to draw conclusions. The results of student analysis and discussion are then discussed with the teacher through class discussion.

The importance of this research is to provide in-depth information about students' mastery of concepts in light wave material after participating in structured inquiry learning assisted by virtual laboratories and real laboratories.

\section{Method}

\subsection{Research design}

This study uses an experimental mixed method design with a one-group pretest-posttest model [21] The data in this study are quantitative and qualitative. The study began by taking qualitative data consisting of interviews to determine the condition of learning physics before treatment. The second stage consisted of obtaining quantitative and qualitative data by giving pretest questions to find out the mastery of initial concepts related to students answering questions related to light wave material. Then, a session implementing structured inquiry models assisted by virtual laboratories was carried out. In the final step, both a post-test and an interview were conducted to find out student reasoning around the material learned.

Interviews before and after treatment are conducted using different open-ended questions. The purposive sampling 
TABLE II. Indicator of student's concept questions

\begin{tabular}{|c|c|}
\hline Item & Indicator Competency \\
\hline Number & Achievement \\
\hline 1 & $\begin{array}{l}\text { Determine phenomena that } \\
\text { will occur when two incoherent } \\
\text { light sources are combined. }\end{array}$ \\
\hline 2 & $\begin{array}{c}\text { Determine students' conceptions } \\
\text { of destructive interference in } \\
\text { transverse waves. }\end{array}$ \\
\hline 3 & $\begin{array}{l}\text { Determine the effect } \\
\text { of wavelength on the interference } \\
\text { pattern produced on the screen. }\end{array}$ \\
\hline 4 & $\begin{array}{c}\text { Determine the quantities that effect } \\
\text { the magnitude of the angle } \theta \text {. }\end{array}$ \\
\hline 5 & $\begin{array}{l}\text { Determine the quantities that must } \\
\text { be changed to widen the distance } \\
\text { between light patterns in a } \\
\text { double slit interference pattern. }\end{array}$ \\
\hline 6 & $\begin{array}{c}\text { Determine of the effect of layer } \\
\text { thickness on patterns formed } \\
\text { in thin layer interference. }\end{array}$ \\
\hline 7 & $\begin{array}{l}\text { Determine interference in a thin } \\
\text { layer where students are asked to } \\
\text { determine the dominant color of } \\
\text { light reflected from a thin } \\
\text { layer of oil. }\end{array}$ \\
\hline 8 & $\begin{array}{l}\text { Determine a single slit diffraction } \\
\text { in which students are asked } \\
\text { to determine the changes that will } \\
\text { occur in the central bright } \\
\text { width when the quantities that } \\
\text { influence it are changed. }\end{array}$ \\
\hline 9 & $\begin{array}{l}\text { Determine a single slit diffraction } \\
\text { in which students are asked to } \\
\text { determine changes in the center of } \\
\text { light width when the color of the } \\
\text { light source used is changed. }\end{array}$ \\
\hline 10 & $\begin{array}{l}\text { Determine the quantities that } \\
\text { affect the distance between } \\
\text { consecutive bright patterns on the } \\
\text { screen in the diffraction grid. }\end{array}$ \\
\hline 11 & $\begin{array}{l}\text { Determine the characteristics of } \\
\text { multiple slit interference patterns, } \\
\text { single slit diffraction, and } \\
\text { multiple slit interference. }\end{array}$ \\
\hline
\end{tabular}

technique was used to select interview samples in which six students were selected as respondents who could provide as much relevant information as possible. Interviews were conducted by individuals without any time limit and depending on the response of each student.

\subsection{Participants}

The subjects of this study were 29 students of class XI Science on an even semester of the year 2018/2019 in one of the high schools in Malang, Indonesia. Respondents were selected based on convenience sampling.

\subsection{Research instrument}

The conceptual understanding, or mastery, was measured with the help of two tests on light wave theory consisting of 11 multiple choice questions with open-ended space for supporting the answer (see Appendix A). Both the pre- and post-tests used the same problem, allowing them to be compared to understand changes in student mastery throughout the learning process. Indicators of student concept competencies are shown in Table II.

The test was designed to assess students' conceptual mastery of light wave theory with the implementation of multiple choice questions with open-ended space for argumenting the reasoning. Students can write down their reasons when answering questions. Indicator of number one question (Q1) is determine phenomena that will occur when two incoherent light sources are combined.

Q1 : If the two flashlights are held close together so that they overlap, then directed at a distant screen, the following phenomenon will occur:

1) the light from both flashlights does not interfere

2) cannot produce a stable interference pattern

3) there are interference patterns that can be observed on the screen.

Correct statements are indicated by numbers
A. 1,2 , and 3
B. 1 and 2
C. 1 and 3
D. 2 only
E. 3 only

Reason : ......

- Validation and Student's Accuracy

The conceptual mastery test developed had 11 questions. The questions were reviewed and validated by a group of Physics lecturers. An emprirical validation was also obtained from 100 students who had received light wave theory material to judge the item validity, comparative test difficulty level and question reliability and relevance; from this analysis, one question was found to be inadequate and hence, it was removed from the final instrument.

Analysis of the validity test, the level of difficulty, and the reliability test of the questions using SPSS while the analysis of different power test questions were done with the help of Excel. The empirical validation is carried out to obtain a reliability of 0.782 . The results of validity test, comparative test, difficulty level test, and the reliability test are presented in Table III. 


\begin{tabular}{|c|c|c|c|c|c|c|c|c|}
\hline \multirow[t]{2}{*}{ Item } & \multicolumn{2}{|c|}{ Validity } & \multicolumn{2}{|c|}{ Comparative test } & \multicolumn{2}{|c|}{ Difficulty level } & \multicolumn{2}{|c|}{ Reliability } \\
\hline & $\mathrm{r}$ & Sig & Index & Category & Index & Category & Index & Category \\
\hline 1 & 0.495 & 0.000 & 0.68 & Good & 0.31 & Medium & 0.782 & high \\
\hline 2 & 0.713 & 0.000 & 0.80 & Very Good & 0.72 & easy & & \\
\hline 3 & 0.575 & 0.000 & $0 . .76$ & Very Good & 0.50 & Medium & & \\
\hline 4 & 0.588 & 0.000 & 0.76 & Very Good & 0.45 & Medium & & \\
\hline 5 & 0.767 & 0.000 & 0.92 & Very Good & $0 . .61$ & Medium & & \\
\hline 6 & 0.245 & 0.014 & 0.24 & Enough & 0.55 & Medium & & \\
\hline 7 & 0.595 & 0.000 & 0.84 & Very Good & 0.46 & Medium & & \\
\hline 8 & 0.762 & 0.000 & 0.96 & Very Good & 0.55 & Medium & & \\
\hline 9 & 0.210 & 0.036 & 0.24 & Enough & 0.73 & easy & & \\
\hline 10 & 0.643 & 0.000 & 0.76 & Very Good & 0.61 & Medium & & \\
\hline 11 & $0, .535$ & 0.000 & 0.72 & Very Good & 0.51 & Medium & & \\
\hline
\end{tabular}

\section{- Item validity}

After being tested on students, an item validity test was conducted. Item validity was calculated making use of the biserial coefficients:

$$
r_{p i s}=\frac{M_{p}-M_{t}}{S D_{t}} \sqrt{\frac{p}{q}}
$$

where $r_{\text {pis }}$ are the biserial coefficients, $M_{p}$ and $M_{t}$ are the average count of items answered correctly and average total score, respectively; $S D_{t}$ is the standard deviation, and $p$ and $q$ are the proportion of students who answer right and wrong, respectively.

\section{- Comparative Test}

The comparative test was performed to determine the ability of a problem in distinguishing high-ability students from students who are low ability. The formula to find out the difference between items is as follows.

$$
D_{B}=\frac{B_{A}}{J_{A}}-\frac{B_{B}}{J_{B}},
$$

where $D_{B}$ is the comparative test of items, $B_{A}$ and $B_{B}$ are the number of group participants who answered right and wrong, respectively, and $J_{A}$ and $J_{B}$ are the number of top and bottom group participants.

\subsection{Data analysis}

Descriptive statistical analysis was performed on the pretest and post-test scores because the data were normally distributed and continued with t-test for paired samples to see the difference between the pretest and post-test scores. Furthermore, to see how much improvement in students' mastery of concepts after learning, N-gain calculations was used [21]. The calculation of d-effect size is done to see the strength of the effectiveness of learning towards increasing the student mastery of concepts [22].
A quantitative analysis was carried out on the reasoning provided by students in the conceptual test on light wave theory. On the other hand, the student interviews served as supporting data in order to evaluate whether structured inquirybased learinng assisted by a virtual laboratory had an influence on student conceptual understanding improvement. To analyse the result of students' reason and interviews, constant comparative techniques are used [24]. Then, a categorization (coding) of data is made by comparing the data to obtain several categories. This process is continued until the core categories are not interdependent.

\section{Result and discussion}

The main objective of this research is to find the effectiveness of using virtual laboratories in learning structured inquiry to improve students' mastery of concepts on the topic of light waves with limited testing. Statistical calculations show that the structured inquiry learning method using virtual reality is effective for increasing students' conceptual mastery of light waves. This result is based on the n-gain that is shown in Table IV.

TABLE IV. Descriptive Statistical Analysis and N-gain

\begin{tabular}{ccccc}
\hline & Minimum & Maximum & $\begin{array}{c}\text { Mean } \\
\pm \mathrm{SD}\end{array}$ & Skewness \\
\hline Pretest & 0 & 54.5 & $26.67 \pm 15.36$ & -0.079 \\
Posttest & 45.5 & 100 & $73.62 \pm 15.36$ & -0.329 \\
N-gain & 0.25 & 1 & $0.65 \pm 0.19$ & -0.210 \\
\hline
\end{tabular}

Based on the skewness value, which is in the range between -1 and 1 , it can be seen that the data is normally distributed (Morgan et al., 2011). T-test for paired samples is performed, where the value of $t=-15.885$ is obtained; $d f=28$; and $p=0.000$, so it can be concluded that there are significant differences between the pretest and posttest scores. 
The results of quantitative data analysis showed that structured inquiry learning model assisted by a virtual laboratory can improve students' mastery of concepts on the topic of light wave theory. The results of the t-test for paired samples evidence that there is a significant difference between pre- and post-test scores. In addition, the average $\mathrm{N}$-gain calculation was of 0.65 in the "high" category and 3.00 , very large, for the d-effect size; this is in accordance with previous research which states that learning with inquiry models assisted by virtual laboratories can help students in improving mastery of concepts [25]. The reason for this is that virtual laboratories can assist students in visualizing abstract concepts such as double slit interference and single slit diffraction. Table IV also shows that before the treatment, students got 26.67 as their average score, and the maximum score was only 54.5 out of 100 . In contrast, after being exposed to the Phet virtual laboratory, the average score increases to 73.62 out of 100. These result support the arguments given by students during their corresponding interviews.

The analysis that will be carried out next is done to understand the process of increasing students' mastery of concepts of light wave material in pre- and post-test. It is assumed that an improvement of the student understanding of concepts is reflected in the form of an increase in the number of correct answer in the post-test, as well as in-depth analysis of several questions. The results of the number of questions answered correctly during the pre- and post-test are shown in Fig. 1.

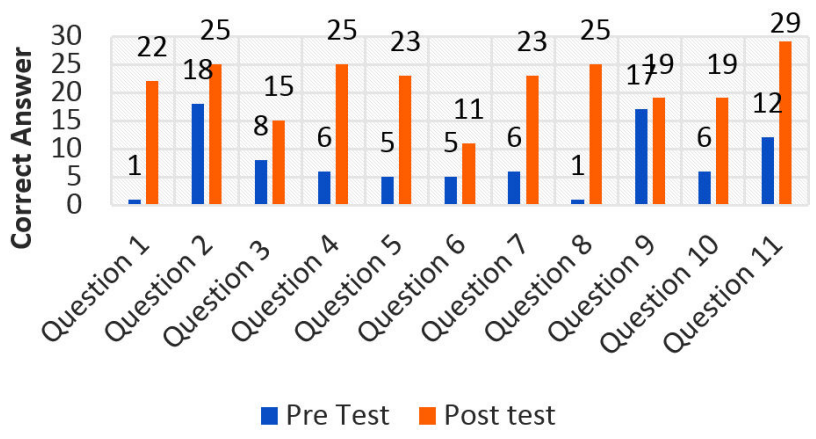

FIGURE 5. The number of students that answered each question correctly.
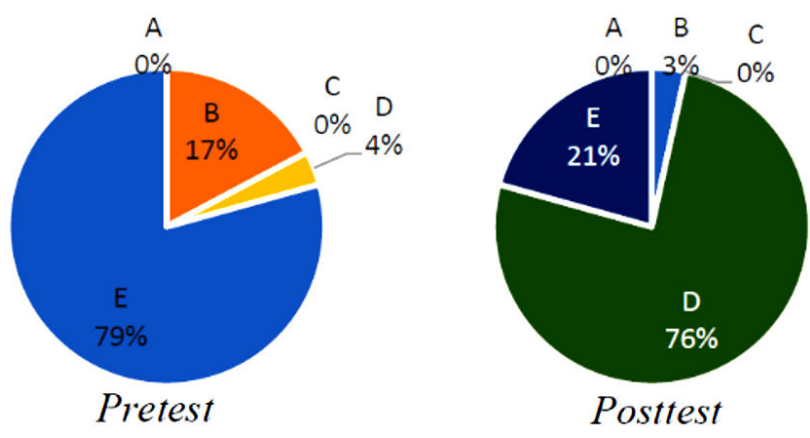

FIgURE 6. Distribution of Student Answers Number 1.

\subsection{Analysis of question number 1 (Q1)}

Question number 1 aims to find out students' conceptions of phenomena that will occur when two incoherent light sources are combined. The correct answer choice for question number 1 is D, "2 only" which states that the phenomenon that will occur when two flashlights are held close together so that overlap then directed at a distant screen are cannot produce a stable interference pattern.

When pretesting, 79\% students chose E, " 3 only" which is sates that "there are interference patterns that can be observed on the screen". Based on the analysis of the interview responses and the written reasoning given, students chose $\mathrm{E}$ because they thought when an interference phenomenon occurs, there must be an interference pattern that can be observed on the screen. An example of the reasoning used to solve this question is shown in Fig. 7.

Meanwhile, students who choose option D, " 2 only", understood that when there are two or more combined sources of light, interference will take place. Students also understand that in order for the interference pattern to be observed, both sources must be coherent and monochromatic. It shows that

\begin{tabular}{l}
\hline Jika dua senter dipegang berdekatan saling tumpang tindih kemudian \\
\hline dikenakan layar puth yang jauh maka akan terdapat pola \\
\hline interferensi yg dapat diamati di layar karena cohaya kedua \\
\hline senter atan saling berpadu sah sama lain. \\
\hline English translations: \\
If two flashlights are held close together and the light \\
overlaps, then dropped on a white screen there will be an \\
interference pattern that can be observed on the screen. \\
This is because the light from the two flashlights blends \\
together.
\end{tabular}

FIGURE 7. Examples of student answers to question number 1 Pre test.

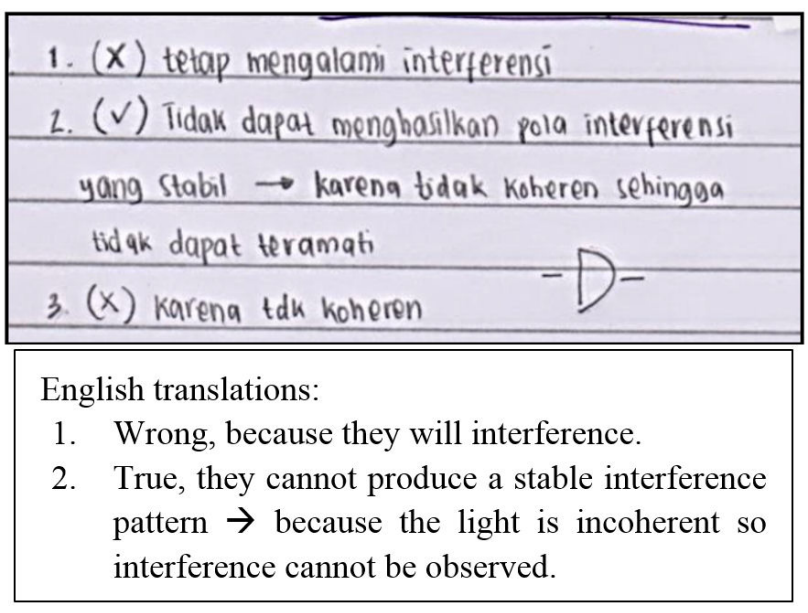

FIGURE 8. Example of student answers to question number 1 Post test. 
students already have a correct understanding after the lesson.

For this particular question, students benefited from a demonstration by combining the light from two flashlights, so students could observe directly that although the two lights from the flashlight were interfering, there was no interference pattern that they could observe. As a consequence of the demonstrations, students become aware of the requirements needed to meet for interference effects to be observed. This proves to be an effective strategy for teaching abstract concepts to sudents, also making them more engaged along the way [21].

\subsection{Analysis of question number 8 (Q8)}

Question number 8 aims to find out the student's conception of a single slit diffraction in which students are asked to determine the changes that will occur in the central bright width when the quantities that influence it are changed. For this specific question, the correct answer was A, "the width of the central bright becomes larger".

When pretesting, $41 \%$ of students chose answer B: "The width of the central bright becomes smaller", $31 \%$ chose answer D: "Half the left center bright pattern disappears so that the center bright width becomes half of the initial width", $24 \%$ chose answer C which is "Half the right center bright pattern disappears so that the center bright width becomes half of the initial width", $0 \%$ chose answer E which is "There is no change in the pattern formed on the screen", and only $4 \%$ chose answer A: "The width of the central bright becomes larger". Based on the interviews and written reasoning of the students, it was concluded that students attempted to use their understanding of geometric optics in answering the problem. Students work on pretest questions with initial abilities and knowledge gained from daily experience. Knowledge is fragmented, causing students to develop misconceptions [22]. Based on the analysis, the student reasoning results showed that students used the concept of geometric optics [6,7,23]. Students commonly stated that light travels in a straight path, failing to realize that light will diffract when passing through a narrow slit. It is because students have not yet grasped the concept of physical
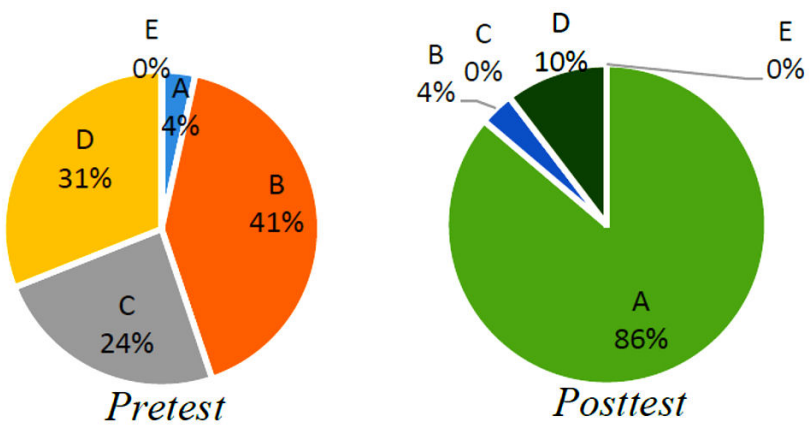

FIGURE 9. Distribution of student answers number 8.
Lebar terang pusat menjadi lebin kecil karena cahaya datang merambat lurus maka apabila celah dipersempit terang pusatjuga ikut menyempit.

English translations:

The width of the central bright becomes smaller because the incoming light propagates straight. So that if the slit is narrowed then the central bright will also be narrowed.

FIGURE 10.Example of student answers to question number 8 Pre test.

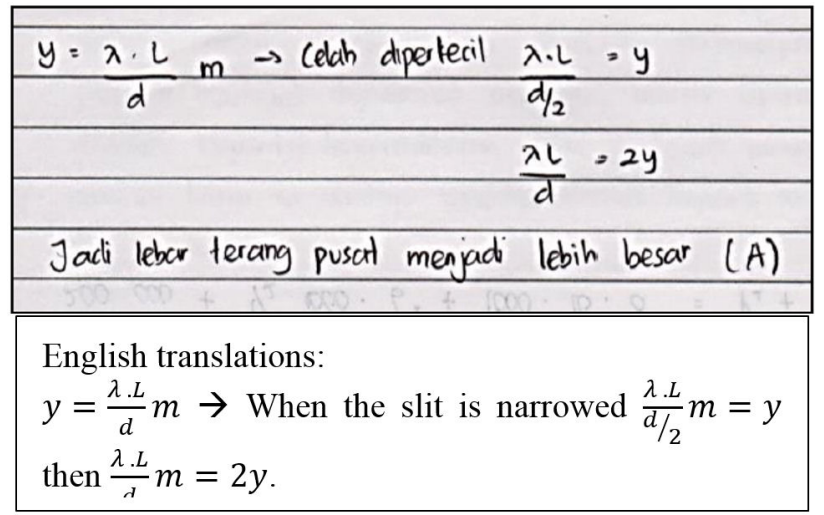

FIGURE 11. Example of student answers to question number 8 Post test.

cal optics, so the concepts of diffraction and image formation are mixed.

Students who answered correctly when pretested were only $4 \%$, but there is a significant increase to $86 \%$ on their posttest. Students who chose option A as the answer on the post-test showed that they have used the concept of physical optics. Students gained the understanding that by closing a half gap-narrowing th width of the slit- the width of the light become greater. It was also seen that students became to explain the behavior o the brightness width formed on the screen, being inversely proportional to the width of the slit.

The performance of students in question 8 is caused because during learning students conduct simulations of double slit interference experiments using wave interference simulations in PhET. Through simulation experiments, students change the distance of the screen to the slit, the width of the slit/distance between slits, and the wavelength of the light source to determine the changes that occur in the patterns formed on the screen. According to Ref. [29] the use of wave interference simulations in PhET can improve the comprehension of concepts because students can easily change the desired variables and after that they can directly observe the effects on the dependent variable in which case the pattern is formed on the screen.

\subsection{More results of other numbers}

Problem 2 was designed to inspect the conceptions that students might have related to destructive interference in trans- 
verse waves. During the pretest, $62 \%$ of students chose answer B: "2". Based on the analysis of the interview answers and the student written reasoning, it was concluded that they already have a good concept related to destructive interference in transverse waves, but the number of students do not relate it to the concept of opposite phase waves. During the posttest, the number of students who answered correctly increased to $86 \%$. The concept of opposite phase waves was widely used, students explained that destructive interference arises whenever two waves are in opposite phase.

The third problem was intended to evaluate students' understanding of the effect of wavelength on the interference pattern seen on the screen. During the pretest, $59 \%$ of students chose answer $\mathrm{C}$ : is "Bright and dark lines that alternate". Based on the analysis of the interview answers and the reasoning written by students, it was evident that it was thought that an interference pattern must be a pattern of dark and bright light regions; students do not seem to realize that the color of the light source affects the resulting interference pattern. During the posttest, $52 \%$ of students chose answer A, which is "White in the middle with a rainbow on the right and left". Now, most students have understood that each color making up white light produces a pattern of double slit interference where each wavelength produces a maximum pattern by bending at different angles. However, there are still $41 \%$ of students who chose option B, "Just rainbow color". This fact suggests that students tend to forget that white light is the result of the overlap of all polychromatic colors.

Problem 4 was set out to find out students' understanding of the quantities affecting the magnitude of the angle $\theta$. During the pretest, $48 \%$ of students chose answer B, which is "Become half of the initial angle $\theta$ ". Based on the analysis of the interview answers and written responses students think that the distance of the screen to the slits is inversely proportional to the angle. During posttest, $86 \%$ of students chose answer C: "The magnitude does not change". Now, students have understood that the magnitude of the angle $\theta$ does not depend on the distance between the screen to the gap, as indicated by the equation $d \sin \theta=m \lambda$.

Question 5 was directed toward the assesment of student understanding of the quantities that affect the distance between light zones of high intensity for the double slit interference pattern. During the pretest, $42 \%$ of students chose the answer E, which is "(3) only". Based on the analysis of the interview answers and the the written responses, it was concluded that students seem to have the correct intuition that the narrower a slit is, the more light will spread when passing through; however, they did not realize that a change of color in the light source is tantamout to changing the wavelength of incident light. During the posttest, $79 \%$ of students chose answer D: "(2) and (3)". Now, students were found to have understood that changing the color of a light source is the same as changing the wavelength of the light source used.

Problem number 6 aims to find out students' understanding of the effect of the thickness of a layer on patterns formed in thin layer interference. During pretest, $48 \%$ of students chose option B, "No interference occurs at the top". After the proper analysis of students' answers in the interviews and reasoning section, it was seen that, in general, they do not understand that it is not that no interference is occurring, but that destructive interference is taking place. During posttest, $38 \%$ of students chose answer C: "The place has a very thin of layer thickness so that no visible light can interfere constructively". This time, students understood that the thickness of a layer affects the interference pattern that is formed. Nevertheless, there are still $34 \%$ of students who chose answer B. This shows that some students still have difficulty in understanding the interference mechanism that determines the color of a thin layer.

In the case of Problem 7, students were inquired about determining the dominant color of the reflected light from a thin layer of oil. During pretest, $72 \%$ of students chose answer A, which is "Violet". Analysis of interviews and written reasoning given by students showed that only common knowledge was used, instead of any scientific explanation. During posttest, $79 \%$ of students chose answer B: "Blue". Students realized that when the light reflected from the upper and lower surface of the layer, both undergoes a $180^{\circ}$ phase change, so that light will be subjected to constructive interference based on the equation $2 t=m(\lambda / n)$.

Problem 9 was aimed to determine students' conception of a single slit diffraction, where students were asked to find out the effect of changing the light source color on the width of the central light zone of high intensity. During pretest, $59 \%$ of students chose option E: "Becomes 2/3 times the initial width", but based on the analysis of the interview answers and the argumentative reasons given, students tend to directly compare the wavelength of the source used without knowing the underlying concepts. During posttest, students who chose $\mathrm{E}$ increased to $66 \%$. Now, students have used the concept of the effect of wavelengths on the width of the central bright, they realize that changing the color of the light source used means the same as changing the wavelength of the light source.

Problem 10 was inteded to find out students' understanding of the quantities that affect the distance between sequential bright patterns on the screen in the diffraction grid. After the pretest, $34 \%$ of students chose answer C: "(2) and (3)". Based on the answers given by students, it was concluded that they tended to re-describing the answer without giving a meaningful reason. The post-test results showed a share of $66 \%$ of students that chose answer B, "(1) and (4)". It is clear that students had now understood that the distance between bright patterns on screen is proportional to the light source wavelength and the distance of the screen to the slits, but inversely proportional to the gap between slits.

Question 11 was planned to determine the student understanding on the characteristics of the double slit interference, the single slit diffraction, and multiple-slit interference patterns. During pretest, $41 \%$ of students chose answer A, which is " 1,2 , and 3". Based on the analysis of the answers, it was shown that students can understand the characteristics of 
multiple slit interference patterns well, but they have difficulty in distinguishing between the characteristics of double slit interference patterns and single slit diffraction patterns. During posttest, all students chose answer C, which is " 2 , 1, and 3". It was concluded that students had understood the characteristics of each diffraction and interference pattern and were capable of distinguishing the patterns of double slit interference, single slit diffraction, and diffraction grating accurately.

\subsection{Result of the interviews}

The results of student interviews show that learning with a structured inquiry model assisted by a virtual laboratory enhances student understanding of concepts on light wave theory. Evidence of this are interview responses, where students state that it had become easier to distinguish the characteristics of multiple-slit interference patterns, single slit diffraction, and diffraction grating after conducting ecperiments through the virtual laboratory due to the fact that they can observe the patterns directly in each situation. In addition, the reasons for the students' answers on the pretest and posttest show that students no longer only use their naive intuition in answering but they use the scientific conceptions they have acquired during learning.

\section{Conclusion and suggestion}

Based on the results of the analysis and discussion of the results of the study, it was concluded that structured inquiry learning assisted by a virtual laboratory is effective in increasing the concept proficiency on light waves. From the final interview, it was found that students felt more confident and said that they could master the concepts taught after learning with a structured inquiry model assisted by a virtual laboratory. The existence of resources such as virtual laboratories helps them visualize interference and diffraction phenomena directly. Nevertheless, it turns out that students remain to experience some difficulties related to interference and diffraction of light waves after the instruction. These difficulties are as follows. (1) Students think that when interference phenomena takes place there must be observable interference patterns, (2) students do not realize that each color of white light used in double slit interference experiences different deflections according to the wavelength, (3) students assume that in the thin layer of dark soap there is no interference, (4) students have difficulty in explaining the relationship between wavelengths against the central bright width of a single slit diffraction, and (5) students have difficulty explaining the quantities that affect the distance between bright patterns in diffraction grating. Suggestions for further research are to compare the mastery of the concepts of students who take virtual laboratory-assisted inquiry learning with students who take virtual laboratory and real laboratoryassisted inquiry learning.

\section{Appendix}

\section{A. The conceptual mastery test in light}

1. If the two flashlights are held close together so that they overlap, then directed at a distant screen, the following phenomenon will occur:

1) The light from both flashlights does not interfere.

2) Cannot produce a stable interference pattern.

3) There are interference patterns that can be observed on the screen.

Correct statements are indicated by numbers
F. 1,2, and 3
G. 1 and 2
H. 1 and 3
I. 2 only
J. 3 only

The Reason: ......

2. The following figure shows two transverse waves. If the two waves interfere with each other, then in what seconds will destructive interference occur?
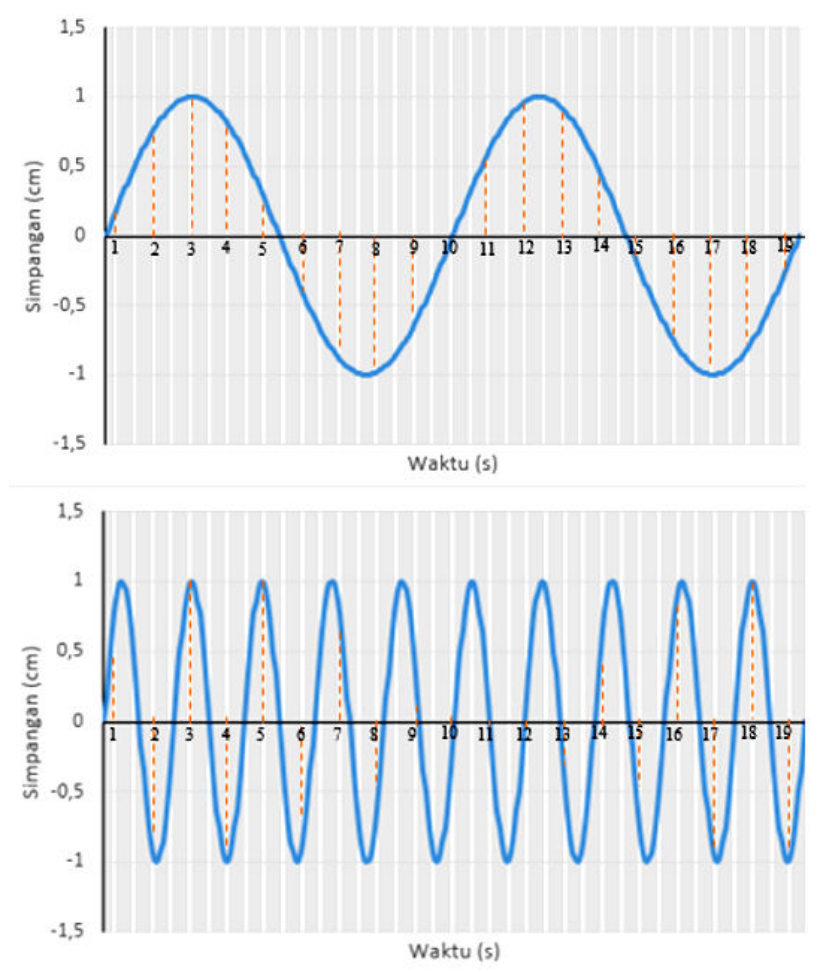

A. 1
B. 2
C. 3
D. 15
E. 17

The reason: .......

3. If in a double slit experiment white light is used as the light source, then the pattern formed on the screen is...

A. White in the middle with a rainbow on the right and left.

B. Just rainbow color.

C. Bright and dark lines that alternate.

D. The screen looks bright, there are no rainbow colors or dark lines.

E. The screen looks dark, there are no rainbow colors or dark lines.

The reason: .....

4. In a double slit experiment, red light is used which is passed on two narrow slits with a gap between slits is $\mathrm{d}$ and a screen placed as far as $\mathrm{L}$ from the slit as shown below.

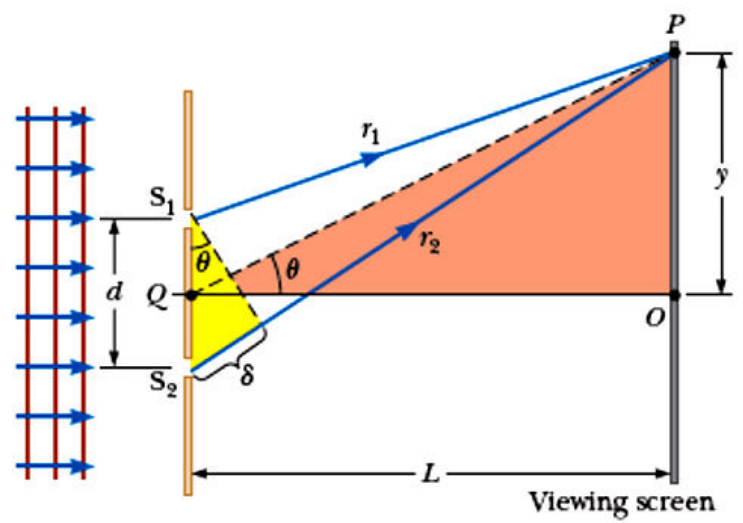

If the screen is moved away from the slits so that the distance between the screen and the slits becomes $2 L$, then what happens to the angle $\theta$ ?
A. Become one quarter of the initial angle.
B. Become half of the initial angle.
C. The magnitude does not change.
D. Becomes two times from the initial angle.
E. Becomes four times from the initial angle.

The reason: .....
5. Light from a blue laser passes through a double narrow slits then hits the white screen so that it forms a dark and bright pattern on the screen. Then do the following treatment.

(1) Bring the screen closer to the slits.

(2) Replacing the blue laser with the red laser.

(3) Replacing the slits with a slits that has a smaller gap between slits.

What can be done to widen the distance between bright patterns is...
A. (1), (2), and (3)
B. (1) and (2)
C. (1) and (3)
D. (2) and (3)
E. (3) only

The reason: .....

6. The thin layer of soap is held vertically in the air. When white light illuminates it, the layer looks like the following picture.

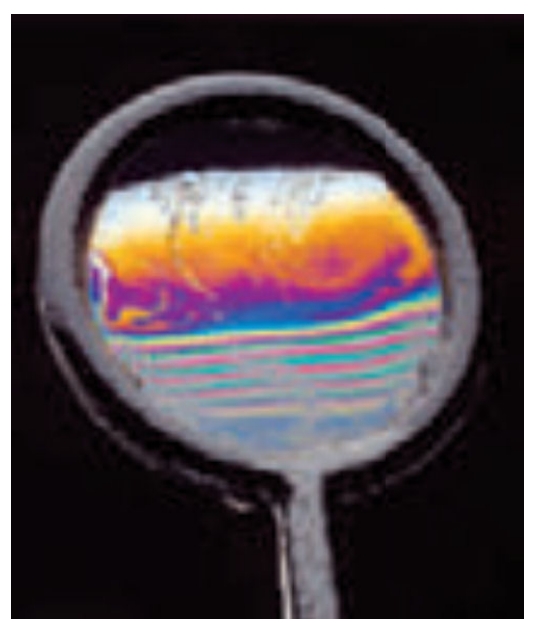

Note that the layer looks dark at the top. The correct statement regarding the incident is...

A. At that place there is no layer of soap.

B. No interference occurs at the top.

C. The place has a very thin of layer thickness so that no visible light can interfere. constructively

D. The place has a layer thickness greater than half of the visible light's wavelength.

The reason: ......

7. The thin layer of liquid $(n=1,2)$ that floats on water is lighted by white light that is close to the normal surface line. This layer thickness is $200 \mathrm{~nm}$. The color of light visible to our eyes is... 
Table of wavelength for each color.

\begin{tabular}{cc}
\hline Color & Wavelength $(\mathrm{nm})$ \\
\hline Violet & $380-450$ \\
Blue & $450-495$ \\
Green & $495-570$ \\
Yellow & $570-590$ \\
Orange & $590-620$ \\
Red & $620-750$ \\
\hline
\end{tabular}
A. Violet.
B. Blue.
C. Green.
D. Yellow.
E. Orange.

The reason: .......

8. In a single slit diffraction experiment, blue light is passed through the slit then hits the screen. What happens to the pattern that forms when the left half of the narrow alit is closed?
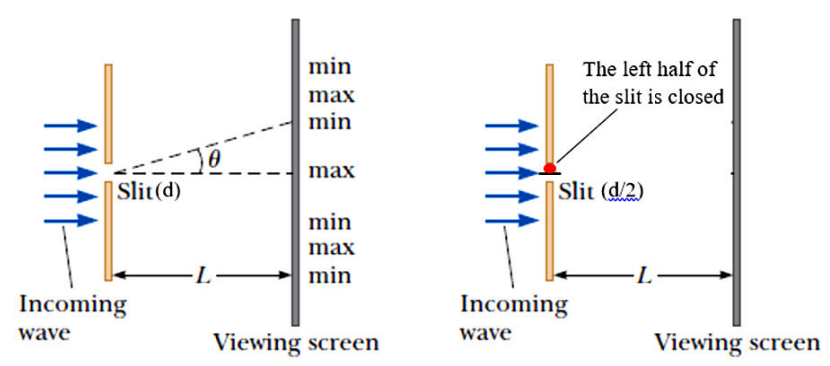

A. The width of the central bright becomes larger.

B. The width of the central bright becomes smaller.

C. Half the right center bright pattern disappears so that the center bright width becomes half of the initial width.

D. Half the left center bright pattern disappears so that the center bright width becomes half of the initial width.

E. There is no change in the pattern formed on the screen.

The reason:

9. Single slit diffraction experiments were carried out using green light. If the green light in the experiment is replaced with red light, how will the changes occur in the center of the bright width? $\left(\lambda_{\text {green }}=500 \mathrm{~nm}\right.$; $\left.\lambda_{\text {red }}=750 \mathrm{~nm}\right)$.
A. There is no change, the width of the center of light does not depend on wavelength.

B. Becomes $1 / 3$ times the initial width.

C. Become 3 times the initial width.

D. Becomes $2 / 3$ times the initial width.

E. Becomes $2 / 3$ times the initial width.

The reason: .......

10. Ultraviolet light with a wavelength of $350 \mathrm{~nm}$ comes on a diffraction grating with a width between slits $d$ and the screen as far as $L$, then the location of its bright patterns is marked on the screen. Furthermore, red light with a wavelength of $700 \mathrm{~nm}$ is passed on the diffraction grating to form another diffraction pattern on the screen. Bright patterns will be located on the signs that were made before on the screen if:

(1) The screen is moved to $L / 2$ distance from the diffraction grating.

(2) The screen is moved to $2 L$ distance from the diffraction grating.

(3) The diffraction grating is replaced by a diffraction grating which has a gap between slits $d / 2$.

(4) The diffraction grating is replaced by a diffraction grating which has a gap between slits $2 d$.

Correct statements are indicated by numbers...
A. (1) and (3)
B. (1) and (4)
C. (2) and (3)
D. (2) only
E. (4) only

The reason: .......

11. The following pictures show a dark and light pattern on the screen formed by several experiments.

Figure 1:

Figure 2:

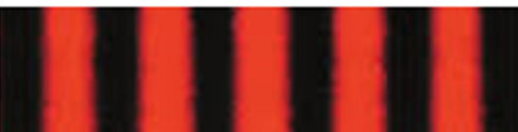

Figure 3:

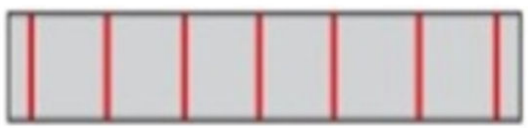


The patterns formed from double slit interference experiments, single slit diffraction, and multiple slit interference (diffraction grating) are respectively shown by the number picture...
A. 1, 2, dan 3 .
B. 2, 3, dan 1 .
C. 2, 1, dan 3 .
D. 3,2 , dan 1 .
E. 3, 1, dan 2 .

The reason:

\section{B. Interview guide before treatment structured inquiry-based learning assisted by a virtual lab- oratory}

1. How do you feel when you study physics?

2. What are the difficulties that you encounter when studying physics?

3. How are the physics learning activities carried out at school now?

4. Can the activity help you in mastering the concepts being taught?

5. Did you ever do practical activities during physics learning?

6. Are you trained to make a hypothesis which is then investigated and proven true?
7. Have you been invited to do practical activities through a virtual laboratory media?

8. How do you expect to learn physics?

\section{Interview guide after treatment structured inquiry-based learning assisted by a virtual lab- oratory}

1. Does the structured inquiry model assisted by a virtual laboratory or real laboratory facilitate you in mastering the physics concepts that have been taught?

2. Which activities can help you master the concepts taught?

3. What difficulties did you encounter when learning physics by using a structured inquiry model assisted by a virtual laboratory or real laboratory?

4. Have practicum activities either directly or through a virtual laboratory been used effectively and can help you master the concepts taught?

5. Is the virtual laboratory or real laboratory assisted structured inquiry model suitable for Light Wave material?

6. What needs to be improved from learning physics using a virtual laboratory or real laboratory assisted structured inquiry model?
1. C. A. Hapsoro and H. Susanto, Penerapan pembelajaran problem based instruction berbantuan alat peraga pada materi cahaya di SMP, J. Pendedik. Fis. Indones. 7 (2011) 28, https : //doi.org/10.15294/jpfi.v7i1.1065

2. S. Sutopo, Students' Understanding of Fundamental Concepts of Mechanical Wave, Indones. J. Phys. Educ. 12 (2016) 41, https://doi.org/10.15294/jpfi.v12i1.3804

3. L. Jumadin, A. Hidayat, and S. Sutopo, Perlunya pembelajaran modelling instruction pada materi gelombang, J. Pendedik. Teor. Penelit. Pengemb. 2 (2017) 325.

4. N. Gultepe, A. Yalcin Celik, and Z. Kilic, Exploring Effects of High School Students' Mathematical Processing Skills and Conceptual Understanding of Chemical Concepts on Algorithmic Problem Solving, Aust. J. Teach. Educ. 38 (2013) 7, https://doi.org/10.14221/ ajte.2013v38n10.1

5. A. Istyowati, S. Kusairi, and S. K. Handayanto, Analisis pembelajaran dan kesulitan siswa SMA kelas XI terhadap penguasaan konsep Fisika, Res. Rep. 2017 (2017) 237.

6. S. K. Sengören, How do Turkish high school graduates use the wave theory of light to explain optics phenom- ena?, Phys. Educ. 45 (2010) 253, https: //doi.org/10. $1088 / 0031-9120 / 45 / 3 / 005$

7. B. S. Ambrose, P. S. Shaffer, R. N. Steinberg, and L. C. McDermott, An investigation of student understanding of single-slit diffraction and double-slit interference, Am. J. Phys. 67 (1999) 146, https://doi.org/10.1119/1.19210.

8. T. Rabe and H. F. Mikelskis, The Role of Language in Learning Physics with Computer-Based Multimedia, in Contributions from Scinece Education Research, edited by R. Pintó and D. Couso (Springer, Dordrecht, 2007), https ://doi .org/ 10.1007/978-1-4020-5032-9_37

9. V. Mešić, E. Hajder, K. Neumann, and N. Erceg, Comparing different approaches to visualizing light waves: An experimental study on teaching wave optics, Phys. Rev. Phys. Educ. Res. 12 (2016) 010135, https://doi.org/10.1103/ PhysRevPhysEducRes.12.010135

10. L. Lestari, R. W. Akhdinirwanto, and A. Ashari, Peningkatan Pemecahan Masalah Melalui Model Pembelajaran Cooperative Integrated Reading And Compotition (CIRC) Pada SMP Negeri 4 Wadaslintang, J. Berk. Pendidik. Fis. 3 (2013) 178. 
11. S. B. McKagan, K. K. Perkins, and M. Dubson, Developing and researching PhET simulations for teaching quantum mechanics, Am. J. Phys. 76 (2008) 406, https://doi.org/ $10.1119 / 1.2885199$

12. B. Atasoy, H. Akkus, and H. Kadayifci, The effect of a conceptual change approach on understanding of students' chemical equilibrium concepts, Res. Sci. Technol. Educ. 27 (2009) 267, https://doi.org/10.1080/02635140903162587

13. F. B. Fernandez, Action research in the physics classroom: the impact of authentic inquiry based learning or instruction on the learning of thermal physics, Asia Pacific Sci. Educ. 3 (2017) 3, https://doi.org/10.1186/s41029-017-0014-z.

14. S. C. J. Long and Y. Bae, Action Research: First-Year Primary School Science Teachers' Conceptions on and Enactment of Science Inquiry in Singapore, Asia Pacific Sci. Educ. 4 (2018) 2, https://doi.org/10.1186/ s41029-017-0017-9.

15. H. Banchi and R. Bell, The many levels of inquiry, Sci. Child. 46 (2008) 26

16. D. Llewellyn, Teaching High School Science Through Inquiry and Argumentation, 2nd ed. (Corwin Press, California, 2013).

17. R. L. Bell, L. Smetana, and I. Binns, Simplifying Inquiry Instruction: Assessing the Inquiry Level of Classroom Activities, Sci. Teach. 72 (2005) 30.

18. A. Colburn, An Inquiry Primer, Sci. Scope 23 (2000) 42.

19. J. Creswell, Riset Pendidikan (Pustaka Pelajar, Jakarta, 2015).

20. R. R. Hake, Interactive-engagement versus traditional methods: A six-thousandstudent survey of mechanics test data for intro- ductory physics courses, Am. J. Phys. 66 (1998) 64, https: //doi.org/10.1119/1.18809

21. G. A. Morgan, N. L. Leech, G. W. Gloeckner, and K. C. Barrett, SPSS for Introductory Statistics, 2nd ed. (Lawrence Erlbaum Associates, New Jersey, 2004).

22. B. G. Glaser and A. L. Strauss, The Discovery of Grounded Theory (Routledge, New York, 2017).

23. T. Jaakkola, S. Nurmi, and K. Veermans, A comparison of students' conceptual understanding of electric circuits in simulation only and simulation-laboratory contexts, J. Res. Sci. Teach. 48 (2010) 71, https: //doi.org/10.1002/tea. 20386

24. H. H. Yolcu and A. GÃ $\frac{1}{4}$ rses, A Demonstration of the Sublimation Process and its Effect on Students' Conceptual Understanding of the Sublimation Concept, J. Turk. Chem. Soc. C 1 (2016) 67.

25. J. L. Docktor and J. P. Mestre, Synthesis of discipline-based education research in physics, Phys. Rev. Spec. Top. Phys. Educ. Res. 10 (2014) 020119, https://doi.org/10.1103/ PhysRevSTPER.10.020119

26. K. Wosilait, P. R. L. Heron, P. S. Shaffer, and L. C. McDermott, Addressing student difficulties in applying a wave model to the interference and diffraction of light, Am. J. Phys. 67 (1999) S5, https://doi.org/10.1119/1.19083

27. C. E. Wieman, W. K. Adams, P. Loeblein, and K. K. Perkins, Phys. Teach. 48 (2010) 225, https://doi.org/ $10.1119 / 1.3361987$ 